\title{
EMPLOYMENT OF STUDENTS FROM PHARMACEUTICAL SPECIALTIES - A PILOT, RETROSPECTIVE-PROSPECTIVE, LONGITUDINAL, QUESTIONNAIRE SURVEY IN TWO CENTERS IN BULGARIA
}

\author{
K. Gergov ${ }^{1}$, H. Burgazliev², E. Hristov ${ }^{1}$, G. Shopov ${ }^{1}$, S. Ognyanov ${ }^{1}$ \\ ${ }^{1}$ Faculty of Chemistry and Pharmacy, University "Sv. Kliment Ohridski" - Sofia, Bulgaria \\ 2Department of Pharmacy, Medical College, University "Prof. Dr. Assen Zlatarov" - Burgas, Bulgaria
}

\begin{abstract}
Aim: To investigate the employment, the desire to work, the work habits and preferences of the students from the pharmaceutical specialties in Bulgaria. Secondary objectives: To analyze the possibilities for employment, to assess its lawfulness, to analyze existing vicious practices, to establish the main problem in fitting together the academic learning process and the work activity. Materials and methods: This was a pilot, retrospective-prospective, longitudinal survey in two centers. We developed a survey questionnaire containing 28 questions of both the open-ended and closed-ended types. The data collection was done using the "Direct individual poll" method. he target group consisted of 165 students from pharmaceutical specialties - pharmacy students from Faculty of Chemistry and Pharmacy, Sofia University "Sv. Kliment Ohridski", and Bachelor-pharmacists from the Medical College, University "Prof. Dr. Assen Zlatarov", Bourgas. The data were processed with the SPSS software. Results: The results are presented in two parts: the first part refers to Bachelors of Pharmacy, and the second - to Masters of Pharmacy. In their majority, the pharmacy students work during their academic studies $-86.4 \%$. The main stimulus for starting work is of financial origin. Of all students working, $56.8 \%$ were hired on an employment contract, while up to one-third worked without any contract at all. In the case of assistant pharmacists $445.3 \%$ of the respondents worked, and the majority of the respondents did it for financial reasons (66.7\%). 86.2\% had a signed employment contract, but $67.9 \%$ were insured on the basis of the minimum salary. Most commonly the students were working in the field of their future specialty in the pharmacy network. Conclusion: The students indicated difficulties in the process of combining their work activity and their studies, a negative attitude to the legal framework and easily discernible negative attitude towards the main field of fulfillment also by the Masters of Pharmacy - working in a pharmacy.
\end{abstract}

Key words: employment of students, pharmacy students, assistant pharmacists, pharmacies

Corresponding author: Assoc. Prof. Emil Hristov, MD, PhD, Faculty of Chemistry and Pharmacy, University "Sv. Kliment Ohridski”, 1 James Bourchier blvd., 1164 Sofia, Bulgaria, Tel. +359 899866 124, e-mail: fheh@chem.uni-sofia.bg

RECEIVED: 30 September 2020; REVISED: 4 October 2020; ACCEPTED: 6 October 2020 


\section{INTRODUCTION}

$\mathrm{F}$ or a large part of the young people to become students means a dream come true as well as pride for their parents. It is typical for the centuries old Bulgarian traditional folk psychology, for parents to desire their children to be highly educated. Parents wish their children to be provided with the opportunity to receive education of the highest degree, regardless of the price they should pay. In the setting of market economy the occurrence of numerous and diverse higher educational facilities in Bulgaria, the opportunities, in the light of the EU membership of Bulgaria, for free movement of people, respectively for the students to choose foreign universities, the increased enrolment of students both in Bulgaria and abroad, turned this historical Bulgarian dream into actual reality. The accessibility to higher education is a real fact for all social layers in Bulgaria, regardless of the social status, the presence of substantive and financial stability, the cultural, ethnical and/or religious differences. The academic learning period encompasses a special stage of human development - the age between 18-19 and 23-25 years. This is a time when young people, already fully matured physically, mentally and socially, have acquired the rights of citizens of legal age and are eager to find their place in life at all cost. Once they have reached the opportunity to study higher education, the main problem for these young people is the financial support for their education and everyday needs. What possibilities do young people have to fit study and work together in the reality of educational practice? Is there a normative regulation in this respect and if yes, is it adequate? Are the higher educational facilities and the state bodies and institutions engaged in the support of this process? Or the possibilities to do supplementary labor are left to be triggered by the mechanisms of the market selfregulation, which cannot always cater to the individual needs? These series of questions, which do not always have a clear answer, prompted us to perform this analysis of the employment among students from the pharmaceutical specialties.

\section{AIMS}

The primary aim of this study was to investigate the desire to work during the academic studies, the actual employment, the work habits and preferences of the students from the pharmaceutical specialties in the higher educational facilities in Bulgaria. Secondary aims: to analyze the possibilities for employment, to evaluate its lawfulness, to analyze any existing vicious practices, to establish the main problems with fitting the study process and work activity together.

\section{MATERIALS AND METHODS}

Study design - a pilot, retrospective-prospective, longitudinal, double center, survey in Bulgaria. Time period of the study was from December 2018 until December 2019. The study was conducted in two basic fields.

Field one: documentary analysis of published and valid normative acts in order to determine the legal environment for performing labor activity by students with pharmaceutical specialties during their academic studies. The main target was the work in a pharmacy. We analyzed the legal possibilities for such activity set forth by: The Labor Code [1], The Law on Medicinal Products in Human Medicine (LMPHM) [2] and the ordinances to it, the Ordinance on the uniform State requirements for acquisition of higher education in the specialty "Pharmacy" for Educational-qualification degree "Master" [3], Ordinance on the uniform State requirements for acquisition of higher education in the specialties of the professional department "Health care" for Educational-qualification degree "Professional Bachelor of..." [4], Professional-qualification characteristics of the specialty "Assistant Pharmacist" for Educational-qualification degree "Professional Bachelor", Medical University Sofia, Medical College "Yordanka Filaretova" [5], Directive 2005/36/EC of the European Parliament and of the Council of 7 September 2005 on the recognition of the professional qualifications [6].

Field two: to analyze the employment and the possibilities for work during the studies and the preferences of the students.

We developed a survey questionnaire containing 28 questions of both the open-ended and closed-ended type. The collection of data was done by the "Direct individual poll" method. The target group of respondents were students from pharmaceutical specialties - pharmacy students from the Faculty of Chemistry and Pharmacy at SU "Sv. Kliment Ohridski" and Bachelors of Pharmacy from Medical College, University "Prof. Dr. Assen Zlatarov", Bourgas. The study included 165 students, as follows: 79 pharmacy students and 86 Bachelors of Pharmacy.

No private data were collected or analyzed, which falls within the scope of the limitations of Regulation (EU) 2016/679 of the European Parliament and of the Council of 27 April 2016 on the protection of natural persons with regard to the processing of personal data and on the free movement of such data (General Data Protection Regulation) [7].

The information from the survey was processed statistically with the SPSS software. We applied descrip- 
tive statistical analysis by determining absolute and relative values, means, medians, modes, standard deviations, minimum, maximum, confidence intervals $90 \%$ at $p<0.05$.

\section{RESULTS}

Analysis of the legal framework. The students in pharmacy and the bachelor students are most often referred to work in the pharmacy network. According to the Law on Medicinal Products in Human Medicine, Art. 219, Par.1 - "The pharmacy is a health facility where the following activities take place: storage, preparation, packaging, controlling, giving consultations, dispensing prescription and non-prescription medicinal products with marketing authorization in the Republic of Bulgaria, of medical devices, of dietetic foods for special medical purposes and infant formulas and follow-on formulas, as well as food supplements, cosmetic and sanitary hygienic means" [2].

General Manager of a pharmacy may be only a Master of Pharmacy where all activities in the pharmacy are performed under his/her guidance and control. The law envisions exceptions where a pharmacy assistant- may also be manager in a pharmacy. Generally, the assistant pharmacist may perform all activities under the control of a Master of Pharmacy with the exception of dispensing prescription medicinal products, control and giving consultations related to the medicinal products.

Medicinal products, which are dispensed without prescription, may be sold in a drug store. The drugstore may also sell products and goods having impact on human health as set forth in ordinance of the Ministry of Health, and medical devices. The drugstore manager must be a medical specialist [8].

The structure, procedures, organization of work of the pharmacies and the medicinal product nomenclature are laid down in ordinance by the Minister of Health [9]. In compliance with the requirements it is forbidden for other persons apart from pharmacists hired on an employment contract and/or pharmacy management contract to work in the reception areas of the pharmacies. It is forbidden for other people apart from Master of Pharmacy and assistant pharmacists hired on an employment contract with the medical treatment facility to work in the pharmacies of the treatment facilities.

Pre-graduation internship in a pharmacy set forth under the procedures of the Ordinance on the uniform State requirements for acquisition of higher education in the specialty "Pharmacy" for the Educational-qualification degree "Master", may take place for students under the control of the Master of Pharmacy after providing the relevant documents from the higher educational facilities [9].

The status of the trainee pharmacists has been laid down in Art.22, Par.5 of Ordinance 28 of 9 December 2008 on the structure, order and organization of the operation of pharmacies and the nomenclature of medicinal products of the Minister of Health and the Rules on continuing education of the Masters of Pharmacy of the Bulgarian Pharmaceutical Union [9].

It is forbidden to perform activities in the pharmacies in Bulgaria, which are not specified in the LMPHM

\section{Part I. Results from the pilot study among the stu- dents in the specialty "Assistant Pharmacist"}

Target population of the study are students from the specialty "Assistant Pharmacist", Medical College, University "Prof. Dr. Assen Zlatarov", Bourgas. The size of the population was 92 students, while 86 respondents took part in the study, i.e. one may say that the target population was comprehensively studied. According to the course of studies the respondents were distributed as specified in Table 1.

Table 1. Respondents according to the training course

\begin{tabular}{|c|c|c|}
\hline Year of study & Number (n) & Relative share (\%) \\
\hline 1 & 32 & 37.2 \\
\hline 2 & 26 & 30.2 \\
\hline 3 & 28 & 32.6 \\
\hline Total & 86 & 100.0 \\
\hline
\end{tabular}

The summarized results show that $45.3 \%$ of the respondents were working during their studies, where $30.2 \%$ of them were the ones who were currently working, while the remaining $15.1 \%$ had worked before the period of the study. The proportion of the working third-year students was the largest one $-70.4 \%$ of them were currently working, while this proportion was the lowest in the first-year students $(9.4 \%)$.

The financial reasons are a leading cause for starting work for $2 / 3$ of the respondents $(66.7 \%)$, while of a relatively small significance is the possibility for career development, a reason given by $13 \%$ of the students who are working. Experience and practical education were selected in $26 \%$ respectively.

Among the working students, more prevalent are the ones working during the entire year (40\%), while the other two groups - working only during vacations or national holidays and working only during the school year - are divided equally (30\%). Most often the stu- 
dents have 12-months work experience $-19.2 \%$ of the working students. $61.5 \%$ of the respondents in this group have a work experience of up to 1 year. The average work experience is about 2 years (43.19 months). Several respondents who have work experience of more than 10 years contribute to this result. The predominant part of the working students had a signed employment contract $(86.2 \%)$, while $6.9 \%$ worked under a civil contract. That many $(6.9 \%)$ are the ones working without having signed an employment contract (Figure 1).

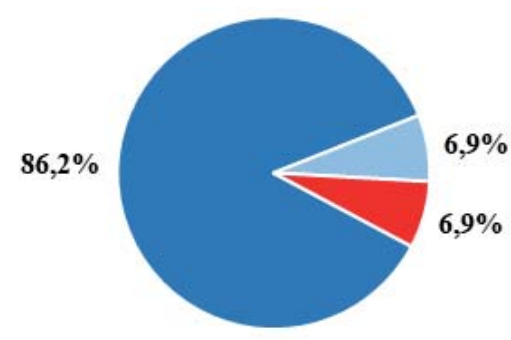

- Employment contract $=$ Civil contract $=$ Without contract

Fig. 1. Presence of a legal employment relationship

With regards to the inclusion of the actual job position in the contract, $40.2 \%$ of the respondents declare that there is discrepancy between the job position written down in the contract and the one, which they actually have in the relevant organization. Almost half $(48.3 \%)$ of the working students at the start of their employment have received a full and exact job description, which described the activities on the job position. For more than $1 / 3$ of this group (37.9\%) no job description was provided, while $13.8 \%$ have received such, but it was incomplete or inexact.

In the majority of the working students $(66.7 \%)$, the actual working hours were fixed in the contract, while in the remainder (33.3\%) there was discrepancy between the working hours fixed in the contract and the actual hours worked. Only $1 / 3(32.1 \%)$ of the students who have a signed employment contract have been insured on the real amount of their wages, while the predominant part $(67.9 \%)$ are insured on the basis of the minimum working salary (Figure 2).

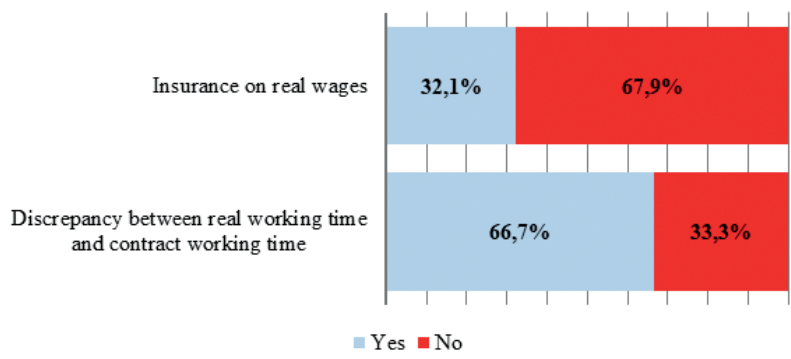

Fig. 2. Social insurance and working hours (n-29)
Fitting work and study together is related to certain difficulties. The results from the study show that most commonly these occur when using leaves (13.8\%). For $10.3 \%$ such difficulties are encountered when preparing the schedule. For other $10.3 \%$ the difficulties manifest themselves both when using the leave and when preparing the schedule. The predominant part $(65.6 \%)$ of the working students indicated that they do not encounter the difficulties mentioned above.

A significant share $-85 \%$ of the working students evaluate their work as related to the specialty, which they study. For more than $1 / 3(38.1 \%)$ of the working students, the work in their field was tied to a program for professional development (i.e. "Student practical training"), while for the majority (61.9\%) starting work was not linked to the opportunities provided by these programs.

The students working in the field of their future specialty most often work in a pharmacy (retail of medicinal products) $-90.9 \%$, followed by consulting activity in pharmacies, medicinal product wholesalers or pharmaceutical companies $-18.2 \%$. Regarding the amount of wages, the processed data shows that most often it is between BGN 3.00 and BGN 4.99 per hour. The legal subjects, connected to retailing (pharmacies) are the predominant employer for the students working in the field of their specialty. A small part $(5.6 \%)$ of the students working in a pharmacy, had taken night shifts (Table 2).

Table 2. Type of work activity, salary and organization of the working hours

\begin{tabular}{|l|c|}
\hline Activity & Relative share (\%)* \\
\hline Retail (pharmacy) & 90.9 \\
\hline Wholesaling (warehouse) & 9.1 \\
\hline Representative office & 4.5 \\
\hline Consulting activity & 18.2 \\
\hline Other & 9.1 \\
\hline *the amount exceeds 100\%, because some students have \\
\hline worked or currently work at two jobs \\
\hline Hourly wage* & Relative share (\%) \\
\hline BGN 3.99 /hour & 33.3 \\
\hline BGN 4.99 /hour & 38.1 \\
\hline BGN 5.99 /hour & 14.3 \\
\hline BGN 6.99 /hour & 9.5 \\
\hline More than BGN 7 /hour & 4.8 \\
\hline *1 Euro=1.95583 BGN & Relative share (\%) \\
\hline Shifts/Being on duty & 5.6 \\
\hline Night shift & 55.6 \\
\hline Day shifts - any & 5.6 \\
\hline Day shifts - morning & 33.3 \\
\hline Day shifts - afternoon & \\
\hline
\end{tabular}


The analysis of the main activities performed by the students on the job indicates that the largest share is processing of deliveries of products and consulting patients about cosmetic products and food supplements. The two-dimensional analysis showed that with the last two levels there are students who are in a more advanced course of studies. With respect to the work experience (years of service) though, no relationships may be found these activities were performed both by students with minimal work experience (1 month) and by the students with work experience of more than 10 years.

The control of a Master of Pharmacy over the activities performed by the students was permanent in $36.8 \%$ of the working students, while in very rare cases they had to work without such control - as indicated by $26.3 \%$ of the respondents.
All students working in a pharmacy know that it is illegal to dispense medicinal products on their own, where for $55.6 \%$ this caused some concern. They know it is not right, but $11.1 \%$ reported they are not concerned, while $33.3 \%$ declared they were acquainted with the legal statutes and had never dispensed medicinal products.

More than $2 / 3(72.2 \%)$ of the respondents believe they have not committed any mistakes during their work at the pharmacy. $5.6 \%$ believe they have committed mistakes, while $22.2 \%$ do not know or do not remember. Among those who believe or do not know if they have committed mistakes the prevalent opinion is that this is due to insufficient control and help by the Master of Pharmacy (Tables 3 ).

$72.2 \%$ of the working students have definitely positive opinion about the practicing of the pharmaceutical profession in a pharmacy (Figure 3).

Table 3. Activities in a pharmacy

\begin{tabular}{|c|c|}
\hline Activities in a pharmacy & Relative share (\%) * \\
\hline Processing deliveries, checking expiry dates, hygienic activities & 88.9 \\
\hline Consulting patients in the field of cosmetic products and/or food supplements & 50.0 \\
\hline Consulting patients about all existing products in the pharmacy and their dispensing & 38.9 \\
\hline Dispensing medicinal products reimbursed by NHIF & 16.7 \\
\hline Dispensing medicinal products containing narcotic substances & 22.2 \\
\hline \multicolumn{2}{|l|}{ *it exceeds $100 \%$, because one or more activities may be indicated here } \\
\hline Performing the activity under the supervision of a Master of Pharmacy & Relative share (\%)* \\
\hline Never & 36.8 \\
\hline Very rarely & 26.3 \\
\hline Rarely & 5.3 \\
\hline Often & 10.5 \\
\hline Very often & 10.5 \\
\hline Almost all the time & 10.5 \\
\hline \multicolumn{2}{|l|}{ Dispensing medicinal products without the supervision of a Master of Pharmacy } \\
\hline Being aware of the legal status and attitude towards their enforcement & Relative share (\%) \\
\hline He/she knows it is not right and is concerned & 55.6 \\
\hline He/she knows it is not right, but is not concerned & 11.1 \\
\hline He/she knows it is not right and has not dispensed medicinal products & 33.3 \\
\hline Have you made mistakes at work? & Relative share (\%) \\
\hline He/she not make mistakes & 72.2 \\
\hline He/she doesn't know, he/shw doesn't remember & 22.2 \\
\hline He/she thinks that have not committed any mistakes & 5.6 \\
\hline
\end{tabular}

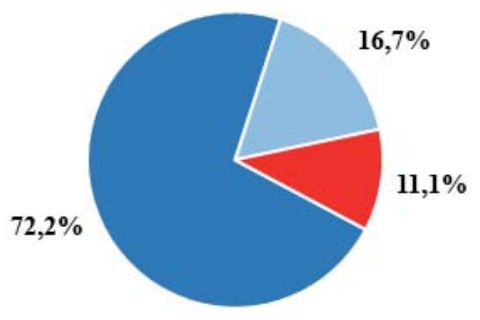

- Definitely positive

- Rather positive

- Definitely negative

Fig. 3. Attitude towards the work in a pharmacy (n-18) 
The majority of the working students $(57.1 \%)$ indicated that compromises are necessary in order to fit together their duties related to study and work. This categorical position is maintained mainly by the students at more advanced grades of studies. $21.4 \%$ believe that it is rather possible to fit work and study together with compromises, while only $10.7 \%$ are categorical that work does not interfere with studying

According to $22.2 \%$ of the working students the higher educational school encourages to a greater or lesser degree their desire to work, while half $(51.9 \%)$ find the attitude of the higher educational school towards them as neutral (Figure 4). $25.9 \%$ find the attitude of the higher educational school rather negative.

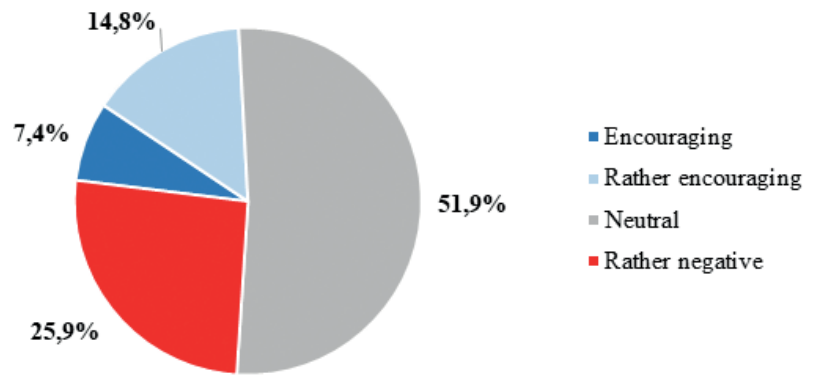

Fig. 4. Attitude of the higher school to the working students (n-28)

Part II. Results from the pilot study among the students from the "Pharmacy" specialty

Target population of the study were students from the "Pharmacy" specialty of the Faculty of Chemistry and Pharmacy at Sofia University "St. Kliment Ohridski“ (Table 4 - data about the surveyed population and the obtained sample). The study was conducted among 2nd; 4th and 5th-year students.

Table 4. Study population

\begin{tabular}{|l|c|c|}
\hline \multicolumn{3}{|c|}{ Respondents according to the year of studies } \\
\hline Year of studies & $\begin{array}{c}\text { Number of } \\
\text { students (N) }\end{array}$ & $\begin{array}{c}\text { Number of } \\
\text { respondents } \\
\text { (n) }\end{array}$ \\
\hline 2nd & 74 & 3 \\
\hline 4th & 64 & 24 \\
\hline 5th & 59 & 45 \\
\hline Graduated assistant pharmacists & 54 & 7 \\
\hline Total & 251 & 79 \\
\hline \multicolumn{1}{|c|}{ Work during studies } \\
\hline Number of respondents n-79 & Relative share (\%) \\
\hline Currently working & \multicolumn{2}{|c|}{62.0} \\
\hline Have worked before & \multicolumn{2}{|c|}{16.5} \\
\hline Not working & \multicolumn{2}{|c|}{} \\
\hline
\end{tabular}

Considering that the target population was partially studied, i.e. based on a sample, whe specifed the size of the sample error for each of the key questions.

The summarized results show that $83.5 \%$ of the respondents work during their studies, where $62.0 \%$ of them are the ones who are currently working, while the remaining $21.5 \%$ have worked before the school year, during which the survey took place. At 95\% confidence level, the maximum error of the share of working students is $\pm 8.19 \%$. The actual value of the share of the students working during their studies is in the interval $75.31 \%-91.69 \%$. Under this confidence interval minimum $3 / 4$ of the students in the specialty "Pharmacy" are currently working or have worked during their studies.

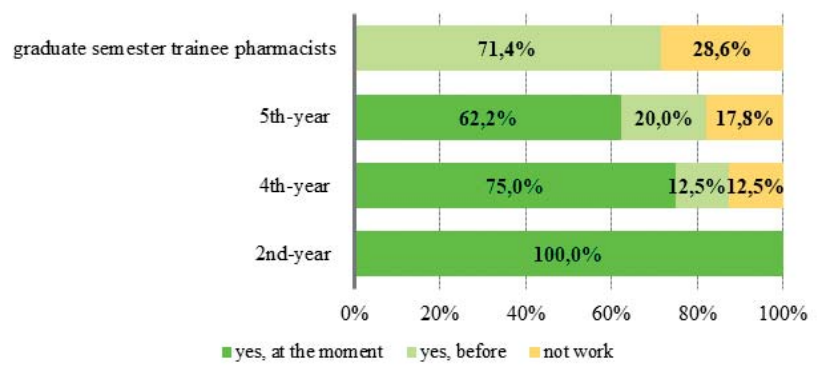

Fig. 5. Share of working students by year of studies

All 2nd-year students included in the sample were currently working. In the 5th-year students there is a share of non-working students, which is $17.8 \%$. Among the students who have completed all semesters, but not graduated, the proportion of non-working students was $28.6 \%$ (Figure 5). Even though a categorical conclusion may not be drawn (due to the small number of 2nd-year respondents in the sample and the lack 3rd-year students), a decrease in the share of currently working students is noticed with more advanced course of studies.

The "Financial reasons" are leading for starting work according to $58 \%$ of the respondents, while the "possibility for career development", which was chosen by $15 \%$ of the working students had the least significance. Experience and practical education were selected by $45 \%$ and $42 \%$ respectively. The sum of all answers exceeded $100 \%$, because the respondents could choose more than one reason for starting work.

Most working students were working over the entire year $(61.5 \%)$. The proportion of respondents who work only during vacations and time of no school is the smallest one $-15.4 \%$. The $23.1 \%$ work during the school year only.

The average work experience is about 2.5 years (30.92 months), the median is 2 years (24 months), 
while the most common work experience is 3 years (36 months) - in $16.7 \%$ of the working students. $40.0 \%$ of the working students have up to 1 year (inclusive) work experience. $26.7 \%$ of the respondents have more than 3-year work experience.

A little more than half of the working students (52.3\%) have a signed employment contracts with their employer. The share of the ones working without an employment contract or a civil contract is significant - more than $1 / 3(35.4 \%)$ of the respondents (Figure $6)$. Once again, more than half $(56.1 \%)$ of the students who work say that the actual job position does not correspond to the one written down in the contract. Bearing in mind the share of the ones working without a contract the data from the study shows that $50.0 \%$ of the working students do not have an employment contract or it does not correspond to their actual duties on the job. The students who, when starting work, have received a full and exact job description, constitute $40.6 \%$ of the working students, the same relative shares belongs also to the students who have not received a job description. The remainder (18.8\%) had received an incomplete or inexact job description.

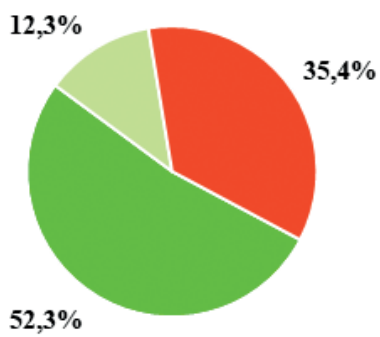

- Employment contract $=$ Civil contract $=$ Without contract

Fig. 6. Presence of legal employment relationship (n-65)
A discrepancy between the actual working hours and the working hours written in the contract was indicated by $42.4 \%$ of the working students (Figure 7 ). Receiving social insurance on the real wages was reported by less than half $(45.0 \%)$ of the respondents from the group of the working students. In $55.0 \%$, the social insurance was based on a wage, which was lower than the one actually received.

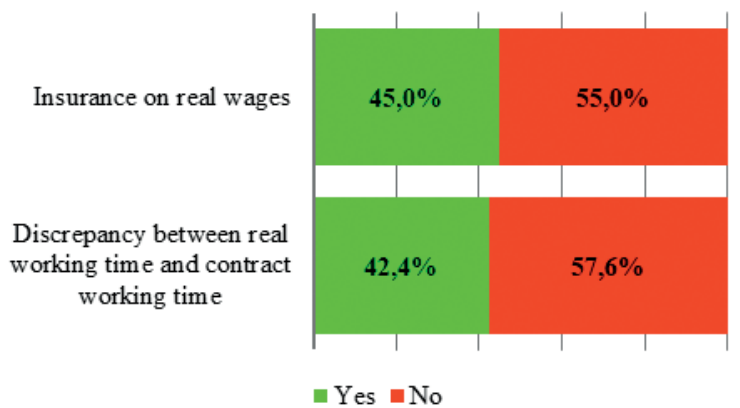

Fig. 7. Social insurance and working hours (n-60)

Fitting work and studies together is related to certain difficulties. Nevertheless, almost $2 / 3$ (64.1\%) of the respondents who work state that they do not encounter such difficulties. Among the remaining 1/3, difficulties are observed both when using leave and when preparing the schedule.

Four out of five (80\%) students, who work, believe that they work on a position related to the specialty they study in the higher school. The remaining $20 \%$ believe that they do not work in the specialty "Pharmacy".

The students working in their specialty most often have a job in a pharmacy (retailing) $(88.7 \%$ ), followed by consulting activity (11.3\%), representative office (9.4\%) and other (regulatory activity) - respectively $7.5 \%$ (Table 5).

Table 5. Type of work activity, salary and organization of the working hours

\begin{tabular}{|l|c|}
\hline Types of work activity (n-53) & Relative share (\%)* \\
\hline Retailing (pharmacy) & 88.7 \\
\hline Wholesaling (warehouse) & 1.9 \\
\hline Representative office & 9.4 \\
\hline Consulting activity & 11.3 \\
\hline Other & 7.5 \\
\hline *it exceeds 100\%, because one or more activities may be indicated here \\
\hline Hourly wage (n-53) & Relative share (\%) \\
\hline BGN 3-3.99/ h & 13.2 \\
\hline BGN 4-4.99/ h & 22.6 \\
\hline BGN 5-5.99/ & 28.3 \\
\hline BGN 6-6.99/h & 28.3 \\
\hline Over BGN 7/ h. & 7.5 \\
\hline *1 Euro=1.95583 BGN & \\
\hline Types of work shifts (n-43) & Relative share (\%) \\
\hline Day shifts, any kind & 74.4 \\
\hline Night & 14.0 \\
\hline Day, morning & 7.0 \\
\hline Day, afternoon & 4.7 \\
\hline
\end{tabular}


The share of working students, whose work is tied to the program "Student practical trainings", is relatively small - only $20.0 \%$, while the majority of them $(80.0 \%)$ reported no such connection.

Regarding the amount of payment, the processed data shows that most commonly it is in the category BGN 5-6.99/h. $-56.6 \%$ of the working students. Students, whose work is related to regulatory activity (7.5\%), fall within the highest hourly wage. Retailing (pharmacy) is the predominant employer of the students working in the field of their specialty. The largest group of students $(74.4 \%)$, who work in a pharmacy mainly undertake all sorts of day shifts, both morning and afternoon ones.

The analysis of the main activities performed by students in a pharmacy shows that almost every one of the working students has performed (at $74.4 \%$ ) consultations of patients about products available in the pharmacy and their dispensing.

The following two activities with high relative proportions are the processing of product deliveries (67.4\%) and patient consultation about cosmetic products (58.1\%). The activities related to medicinal product dispensing also show relatively high shares: $45.5 \%$ with the medicinal products reimbursed by NHIF and $27.9 \%$ with the medicinal products containing narcotic substances.

The two-dimensional analysis shows that there are students who are in the 4th or 5th year of study. In the 4th-year students, the share of the ones who have dispensed MPs reimbursed by NHIF is $30.8 \%$, while in the 2nd-year students no such data was registered. In the 5th-year students, this share is doubled $-60.9 \%$ of these working students have dispensed MPs, while in the 5th-year students who have completed all semesters, this share is $50.0 \%$.

With respect to the medicinal products containing narcotic substances, the two-dimensional analysis of the distribution with the variable year-of-studies, shows the following: the 2nd-year respondents have not dispensed such products; $15.4 \%$ of the 4 th-year respondents have dispensed such products; $34.8 \%$ of the 5th-year respondents indicate they have dispensed such products; $1 / 2$ of the students who have completed all semesters have dispensed such products. The relatively small number of respondents does not provide the opportunity to draw more noteworthy conclusions regarding the statistical significance of the results above.

The control by a Master of Pharmacy over the activities performed by the students was ongoing in $16.3 \%$ of the respondents, while for $30.3 \%$ it happened rarely or very rarely to work without such control (Table
6 ). On the other hand, for almost $1 / 4$ of the respondents they had to perform their duties without control during almost the entire working hours.

All students working in a pharmacy know that it is not lawful to dispense medicinal products, but the results from the study show that almost everyone $-95.3 \%$, has dispensed medicinal products. In a huge part of the respondents $-76.7 \%$, this caused certain concerns.

Table 6. The main activities in a pharmacy (n-43)

\begin{tabular}{|c|c|}
\hline $\begin{array}{l}\text { Types of activities and duties dur- } \\
\text { ing the work in a pharmacy }\end{array}$ & Relative share (\%)* \\
\hline $\begin{array}{l}\text { Consultations of patients about all } \\
\text { available products in the pharmacy } \\
\text { and their dispensing. }\end{array}$ & 74.4 \\
\hline $\begin{array}{l}\text { Processing deliveries, checking } \\
\text { expiry dates, hygienic activities. }\end{array}$ & 67.4 \\
\hline $\begin{array}{l}\text { Consultations of patients in the field } \\
\text { of cosmetic products and/or food } \\
\text { supplements. }\end{array}$ & 58.1 \\
\hline $\begin{array}{l}\text { Dispensing medicinal products } \\
\text { reimbursed by NHIF }\end{array}$ & 45.5 \\
\hline $\begin{array}{l}\text { Dispensing medicinal products } \\
\text { containing narcotic substances. }\end{array}$ & 27.9 \\
\hline \multicolumn{2}{|c|}{$\begin{array}{l}\text { *the amount exceeds } 100 \% \text {, because some students have } \\
\text { indicated } 2 \text { and more duties }\end{array}$} \\
\hline $\begin{array}{l}\text { Supervision by a Master of } \\
\text { Pharmacy(n-43) }\end{array}$ & Relative share (\%) \\
\hline Never & 16.3 \\
\hline Very rarely & 16.3 \\
\hline Rarely & 14.0 \\
\hline Often & 18.6 \\
\hline Very often & 11.6 \\
\hline Almost all the time & 23.3 \\
\hline \multicolumn{2}{|c|}{$\begin{array}{l}\text { Dispensing medicinal products without supervision by a } \\
\text { Master of Pharmacy }(n-43)\end{array}$} \\
\hline $\begin{array}{l}\text { Knowing the legal stipulations and } \\
\text { attitude towards their enforcement }\end{array}$ & Relative share (\%) \\
\hline $\begin{array}{l}\text { He/she knows that is it not right and } \\
\text { is concerned }\end{array}$ & 76.7 \\
\hline $\begin{array}{l}\text { He/she knows that it is not right, but } \\
\text { is not concerned }\end{array}$ & 18.6 \\
\hline He/she has not dispensed MPs & 4.7 \\
\hline
\end{tabular}

Sixty-nine percent $(69.0 \%)$ of the respondents believe they have not committed mistakes during their work in a pharmacy, while $16.7 \%$ do not know or do not remember. Committing a mistake was indicated by $14.3 \%$ of the surveyed students working in a pharmacy. Among the ones who believe or do not know 
if they have committed a mistake, there is a weak prevalence $(54.5 \%)$ of the opinion that the mistakes are due to insufficient control and help by the Master of Pharmacy.

$7.1 \%$ of the working students have categorically positive opinion on the practice of the pharmacy profession in a retail area, while for $28.6 \%$ the attitude rather is positive. $19.0 \%$ have given a neutral answer to the question, while for $35.7 \%$ the expressed attitude is more towards negative. $9.5 \%$ of the respondents in the group of students working in a pharmacy have a categorical negative attitude (Figure 8).
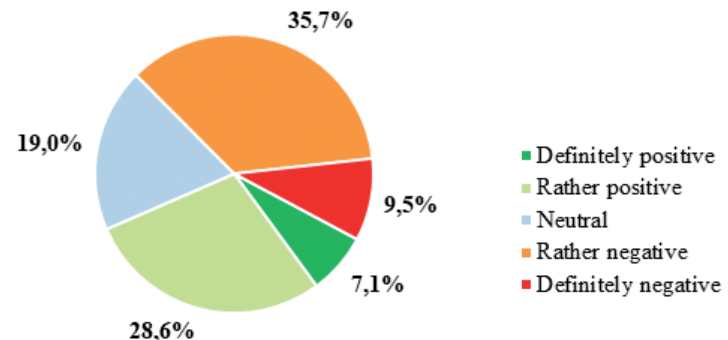

Fig. 8. Attitude towards the work in a pharmacy (n-42)

Among the working students, two groups stand out with respect to the opportunity to fit work and study together without making compromises. The ones maintaining the statement that combining them together is possible, are $50.0 \%$, while the students making the opposite statement are $48.4 \%$ ( $n-64)$.

One fifth $(20.3 \%)$ of the working students evaluates the attitude of the University as encouraging. $28.2 \%$ is the total share of the respondents who perceive the attitude of HS towards their desire to work as negative. The largest share belongs to the group of students according to whom the attitude of HS to the fact that they work is neutral $-51.6 \%$ (Figure 9).

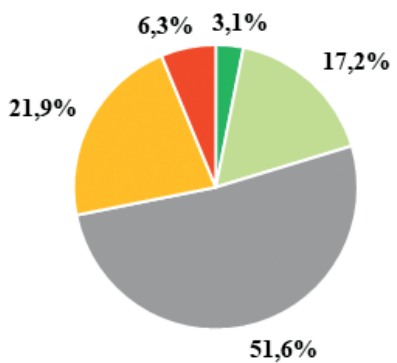

- Encouraging

- Encouraging

- Neutral

" Rather negative

- Negative

Fig. 9. Attitude towards the working students of the University (n-64)

\section{DISCUSSION}

The legal analysis we performed shows that only Master of Pharmacy and assistant pharmacists may work in pharmacies. The hiring of other staff is forbidden where this prohibition is under the so called "enforcement when the reverse is true"- LMPHM stipulates that in the pharmacies of Bulgaria it is forbidden to perform activities, which have not been expressly set forth in the normative acts. Since LMPHM and the regulations to it determine that the activities in the pharmacy shall be performed only by a Master of Pharmacy or an assistant pharmacist, then the hiring of other staff should be deemed inadmissible, respectively unlawful, while at the same time this is also a violation of the Rules of Good Pharmacy Practice [10].

Our study shows that despite the existence of prohibiting texts in the applicable legislation, the pharmacy students and the assistant pharmacists candidate for work in a pharmacy network despite the prohibition for their hiring. Almost half of the students in the "Assistant Pharmacist" specialty $-45.3 \%$, are working during their studies. Not less than $3 / 4$ of the students having the specialty "Pharmacy" are working right now or have worked during their studies $-83.5 \%$. The actual value of the share of students who work during their studies is within the threshold of the confidence interval $75.31 \%-91.69 \%$.

The results obtained are impressive: more than 95\% of the working students are acquainted with the legislation, but nevertheless agree to work during their studies in the pharmacy network and are well aware which activities are not stipulated.

There is a categorical opinion (80.8\%) that it is right for the students to have the opportunity to work in a pharmacy during their studies. According to $58.8 \%$ of the working students it is necessary that the work in a pharmacy during academic studies should be legally regulated, which will lead to less risky situations and better welfare of the students. For 35.3\% this regulation would achieve partial positive changes, while $5.9 \%$ of the working students share the opinion that this regulation would not improve the current status.

A little more than $1 / 3-38.5 \%$ of the respondents believe that the absence of legal framework rather disrupts their desire to work in the field of pharmacy during their studies than helping for their development. Half of the respondents $(53.8 \%)$ believe that the legal framework does not influence in any way the possibility to work, and there is a disperse group of $7.7 \%$, who are of the strange opinion that the legal framework stimulates the fitting together of work and study. We believe that this dispersion is due to the so called "Errors of bias" of the respondents. 
Apart from the serious infringements on the medicinal legislation, the survey established the presence of serious problems and infringements also of the labor legislation as a whole - working without employment contracts, without job descriptions, non-regulated payment, absence of healthcare and social insurance installments, unscheduled work hours, etc. These are suspected problems, which are a "public secret", but are not commented on an institutional level by the interested parties - Ministry of Health, Bulgarian Drug Agency, Regional health inspectorates, the Universities, the Bulgarian Pharmaceutical Union, etc.

Even though this study is a pilot one, acceptable assumptions are made. There are however limitations like: only two centers and a target group of 165 students participated with a total student number nationwide of more than 2000. Anyhow, the data obtained about illegal labor market may be considered statistically reliable and well-founded.

\section{CONCLUSION}

The need of the students to work during their years of study is evident. Categorically the majority of students express an opinion that it is desirable for them to be able to work legally before the mandatory state practical training, which will positively impact their status - professional and financial. The main part of the students work in pharmacies and their work is closely related to the specialty they are studying. The majority of the students working in a pharmacy have an established positive attitude towards the profession. Fitting together of work and study is difficult, and problems exist related to the organization of the study process, on the one hand, and on the other, problems related to the employers. There is an obvious need of regulatory amendments, which can create legal opportunities for labor activity during studying linked to the future professional fulfillment of the students.

\section{REFERENCES}

1. Lex.bg. Labour Code. (Кодекс на труда) (in force since 01.01.1987) [Cited 2020 May 23]. Available from: https:// www.lex.bg/laws/ldoc/1594373121

2. Lex.bg. Bulgarian Law on Medicinal Products in Human Medicine (Закон за лекарствените продукти в хуманната медицина) (in force since 13.04.2007) [Cited 2020 June 23]. Available from: http://www.lex.bg/bg/laws/ldoc/2135549536.

3. Lex.bg. Ordinance on the uniform State requirements for acquisition of higher education in the specialty "Pharmacy" for educational-qualification degree "Master" (in force since 05.04.2005) [Cited 2020 May 10]. Available from: https:// www.lex.bg/laws/ldoc/2135501677

4. Lex.bg. Ordinance on the uniform State requirements for acquisition of higher education in the specialties of the professional department "Health care" for educational-qualification "Professional Bachelor of ..." (in force since 26.09.2008) [Cited 2020 January 10]. Available from: https://lex.bg/en/laws/ Idoc/2135601053

5. MU-Sofia. Medical college "Yordanka Filaretova". Qualification characteristics - "Assistant Pharmacist". [Cited 2020 January 10]. Available from: https://mc.mu-sofia.bg/?page_id=2244

6. Directive 2005/36/EC of the European Parliament and of the Council of 7 September 2005 on the recognition of professional qualifications (Text with EEA relevance). Current consolidated version: (in force since 24.04.2020) [Cited 2020 May 10]. Available from: http://data.europa.eu/eli/dir/2005/36/oj

7. Regulation (EU) $2016 / 679$ of the European Parliament and of the Council of 27 April 2016 on the protection of natural persons with regard to the processing of personal data and on the free movement of such data, and repealing Directive 95/46/ EC (General Data Protection Regulation) Current consolidated version. (in force since 04. 05. 2016) [Cited 2020 June 23]. Available from: http://data.europa.eu/eli/reg/2016/679/oj

8. Lex.bg. Ordinance № 29 of December 9, 2008 on the terms and conditions for the organization of work in the drugstore. Issued by Minister of Health. Bulgaria. (in force since 23.12.2008) [Cited 2020 June 23]. Available from: https:// www.lex.bg/index.php/mobile/ldoc/2135610890

9. Lex.bg. Ordinance № 28 of 9 December 2008 on the structure, order and organization of the operation of pharmacies and the nomenclature of medicinal products. (in force since 23.12.2008) [Cited 2020 June 23]. Available from: https:// www.lex.bg/laws/ldoc/2135610889

10. Good pharmacy practice. Issued by Minister of health. (in force since 10.01.2020), promulgated State gazette V.3. [Cited 2020 June 23]. Available from: https://dv.parliament.bg/ DVWeb/showMaterialDV.jsp;jsessionid=4FABD6516DE61F4 DF5A2260D8B0AC1DC?idMat=144371 